\title{
PROFESIONES SANITARIAS Y LUCHA DE PODERES EN EL MÉXICO DEL SIGLO XIX*
}

\author{
Ana María Carrillo \\ Departamento de Salud Pública - Edificio B, $6^{\circ}$ piso - Facultad de Medicina \\ Universidad Nacional Autónoma de México - Circuito Interior C. P. 04510 - México, D. F.
}

\begin{abstract}
RESUMEN
Establecer su saber como poder, fue uno de los objetivos de los médicos mexicanos del siglo XIX. Para lograrlo, intentaron convencer al Estado y a la población de la superioridad de la medicina autodenominada científica, y lo hicieron por medio de sus asociaciones gremiales y publicaciones periódicas. Pretendieron, asimismo, controlar a aquellas disciplinas que habían comenzado a desarrollarse dentro de la medicina, y combatieron abiertamente las prácticas médicas que invadían el área que ellos consideraban de su competencia exclusiva. En general, buscaron organizar el saber médico, jerarquizarlo, hacerlo asunto de Estado y de estatus económico y social. Las otras profesiones sanitarias reaccionaron colectivamente contra esos intentos de control y exclusión, luchando por su autonomía. En esa centuria, hubo una extensión creciente del campo y de los poderes médicos; en caso de epidemias, por ejemplo, el Estado obligó a la población a recibir atención médica. La relación que en el XIX mexicano hubo entre el conocimiento y procedimientos médicos, por un lado, y la propia organización profesional, otros saberes médicos, el Estado y el mundo profano, por el otro, es una de las claves de la profesionalización de la medicina en México.
\end{abstract}

\section{SUMMARY}

To establish their knowledge as a power base was one of the $19^{\text {th }}$ century Mexican doctors' objectives. In order to achieve that, they tried to convince the State and the population of the superiority of 'scientific medicine', as they refered to it, by means of their professional associations and periodicals. In addition to this, they intended to control the disciplines that had started developing within medicine, and openly fought against medical practices which invaded what they thought was their exclusive domain. In general, they sought to organize medical knowledge, rank it, make it a concern of State and of socio-economic status. Other health professions reacted collectivelly against these attemps at control and exclusion, struggling for their autonomy. In that century there was an accelerated growth in the field of medicine and medical procedures. For instance, in the case of epidemics, the State forced the population to receive medical attention. One of the keys to understand the professionalisation of $19^{\text {th }}$ century Mexican medicine is the relationship between medical knowledges and its procedures, on the one hand, and on the other, the medical profession's own organizations, other medical knowledges, the State and the uninitiated world.

* Presenté una versión preliminar de este trabajo en el IV Congreso Mexicano de Historia de la Ciencia y la Tecnología, Culiacán, 17 de agosto de 1994. 


\section{MEDICINA: DE "OFICIO" A "PROFESIÓN"}

En los cerca de 100 años que transcurrieron desde el fin de la guerra de independencia al fin de la revolución iniciada en 1910, se pasó en México:

- De situaciones de discontinuidad institucional en la enseñanza médica, a la consolidación de las escuelas de medicina en la capital y Guadalajara, y la creación de escuelas médicas en otras ciudades de provincia.

- Del Protomedicato, constituido por unos cuantos facultativos encargados de regular el ejercicio de la medicina pero sin presupuesto para realizar investigación o autoridad para decidir acciones durante las epidemias, y la dispersión de la responsabilidad sanitaria en varias autoridades, a la creación, en 1917, del Departamento de Salubridad dependiente directamente del presidente de la república, con capacidad ejecutiva y jurisdicción en toda la nación.

- De leyes aisladas en materia de salubridad, a la elaboración de códigos sanitarios y el impulso de campañas científicas de salud pública.

- De la recepción de la medicina clínica y experimental europea, a la creación de institutos nacionales de investigación médica.

- De agrupaciones médicas incipientes y fugaces, a la proliferación de asociaciones gremiales, particularmente la Academia Nacional de Medicina.

- De la existencia de lazaretos, más centros de evangelización y aislamiento que instituciones con una función terapéutica, a la construcción, a principios del siglo XX, de hospitales dotados de todos los avances de la ciencia médica de la época.

Este período contiene, pues, la suma de acontecimientos que llevaron a la comunidad médica a modificar sustancialmente muchas de las categorías que habían estado vigentes en la época colonial y - a través de un movimiento no exento de contradicciones de muy diversa índole- a consolidar en México la profesión médica; a institucionalizar su autoridad.

En todo este camino, muchas veces tortuoso, la comunidad médica jugó un papel fundamental al defender sus instituciones, aun en condiciones adversas, y persuadir de la necesidad y utilidad de sus acciones al Estado mexicano, el cual por un lado, financió sus establecimientos de educación, sus agrupaciones gremiales, sus publicaciones científicas y su participación en reuniones nacionales e internacionales, y por otro, sancionó legalmente su enseñanza y su práctica. Fue precisamente en ese proceso en el que la comunidad médica forjó un modelo profesional que se consolidaría a mediados del siglo XX.

Mucho más difícil - y este fenómeno ha sido poco estudiado en México- fue que la medicina académica empezara a ganar la confianza del público - a apoderarse 
del cuerpo de los otros- y aún hoy está lejos de poder impedir que la población recurra a otras prácticas médicas, a pesar de haber dado una larga lucha para lograrlo. Lo anterior es de fundamental importancia pues — como ha sido señalado-1, a diferencia de los físicos o los botánicos, que en el proceso de institucionalización de sus disciplinas requieren básicamente del reconocimiento de sus pares y del apoyo del Estado, en la medicina - como en cualquier otra profesión de consulta- se necesita, además, que el público crea en el valor del conocimiento y la destreza de quien la realiza, con exclusión de otras prácticas.

Desde la época colonial hasta nuestros días, los médicos universitarios han pretendido tener un control total sobre la medicina; han afirmado ser la única autoridad confiable para proporcionar atención médica, y presionado al Estado para que autorice dicho monopolio. Aunque en España y sus colonias se reconoció el aprendizaje universitario como el criterio fundamental que habilitaba a un hombre para ejercer el cuidado médico, en la práctica los médicos universitarios tuvieron que competir con la medicina doméstica y la medicina indígena (esta última tolerada por las Leyes de Indias); la medicina "popular" española, negra y de mezclas (que sí fue perseguida); y la atención prestada por otras profesiones sanitarias, por religiosos y por médicos europeos sin título. Desde entonces, la medicina académica ha tenido que coexistir con otras formas de saber médico, dando así lugar a lo que algunos denominan un modelo plural de atención ${ }^{2}$.

Los médicos españoles y criollos se referían a los que practicaban la medicina "sin temor de Dios", es decir, sin título, como "ministros de la muerte"; y se quejaban de ser oprimidos por esos "intrusos", aunque, en realidad, éstos eran producto de una demanda de atención. La gran competencia que entonces se daba entre los médicos, se debía a que la oferta era mucho mayor que la demanda, a pesar de la escasez de médicos universitarios en la Nueva España (entre 1607 y 1738, por ejemplo, la universidad otorgó sólo 3.35 títulos por año) ${ }^{3}$. En esa época, la medicina tenía limitaciones a nivel mundial, y era todavía más un oficio que una profesión. Los médicos, con excepciones, carecían de un alto estatus; la educación teórica y práctica que recibían era mínima; sus diagnósticos solían ser poco acertados y sus tratamientos, también escasamente eficaces. La medicina no tenía aún el mismo reconocimiento que otras ciencias. De los estudios que era posible realizar en la Real y Pontificia Universidad, los menos prestigiados eran los de medicina. Algunos historiadores han visto en la exigencia de limpieza de sangre que se hacía a los estudiantes de medici-

\footnotetext{
1 FREIDSON, E., (1978), La profesión médica, Barcelona, Península.

2 ZOLlA, C., et al. (1988), Medicina tradicional y enfermedad, México, CIESS.

3 LANNING, J. T., (1985), The Royal Protomedicato. The regulations of the medical profession in the Spanish Empire, Durkham, Duke University Press.
} 
na, una muestra del importante lugar que los médicos tenían en la sociedad4; sin embargo, otros señalan que esta exigencia no se hacía a los futuros militares o abogados, y era, al parecer, más un intento de eliminar el desprestigio de la profesión médica ${ }^{5}$. Esta tesis parece comprobarse cuando se ve que a los cirujanos, así como a los farmacéuticos y a los flebotomianos, también se les exigía, para poder obtener su título, un certificado de limpieza de sagre ${ }^{6}$. Eso sí, los médicos estaban en la cima de la jerarquía de los profesionales de la salud: mientras la suya era vista como una profesión docta, la actividad de los cirujanos, barberos, flebotomianos y parteras, era considerada manual; y como comerciantes eran vistos los farmacéuticos ${ }^{7}$.

Durante años, los médicos criticaron la poca consideración que la sociedad daba a su profesión, al tiempo que se esforzaron por demostrar que la medicina era no sólo una ciencia útil, sino la más útil de las ciencias. En su Mercurio Volante, Bartolache avisaba que el periódico comunicaría noticias de física y medicina: “... dos ciencias de cuya utilidad nadie dudó jamás"8. Aseguraba que otras ciencias podían servir para el adorno o la vanidad; en cambio, sin vivir sano no se podía ser feliz. Sin embargo, reconocía que las escuelas públicas creadas por el monarca habían producido muchos hombres de mérito en teología y jurisprudencia, pero menos en filosofía y medicina. Insistiría sobre la importancia de la medicina en un número posterior de la publicación. En él la defendía de los que se referían a ella como “... arte adivinatoria y conjetural, ciencia mocosa, imperfecta, no sólo falible sino también falsa por la mayor parte" 9 .

En el siglo XIX, la medicina seguía siendo la más prestigiada de las profesiones sanitarias, pero tenía menos prestigio que otras profesiones. Manuel Carpio - destacado clínico y catedrático- denunciaba en 1839, que en México no se respetaba el trabajo de los facultativos y la situación de la ciencia era funesta, a diferencia de otros países donde la medicina y las ciencias todas habían salido de la barbarie, por-

4 Somolinos D., G., (1957), Historia y medicina. Figuras y hechos de la historiografia médica mexicana, México, Imprenta Universitaria.

5 LANNING, J. T., (1985).

6 Ver, por ejemplo, Archivo Histórico de la Facultad de Medicina (AHEM), México, Protomedicato, leg. 1; exps. 2 (flebotomiano), 3 (cirujano) y 8 (farmacéutico); 1,6 y 17 f., 1758, 1768 y 1786-87.

7 FloReS, F. A., (1886), Historia de la medicina en México. Desde la época de los indios hasta la presente, 3 v., México, Secretaría de Fomento. Esta sigue siendo la gran historia de la medicina en México; no ha sido superada, a pesar de que se censura a Flores por no haber citado sus fuentes. La Academia Nacional de Medicina y la Facultad de Medicina de la Universidad Nacional iniciaron, hace tiempo, el proyecto de escribir colectivamente una historia general de la medicina, pero sólo han visto la luz los volúmenes México antiguo (1984) y Medicina novohispana. Siglo XVI (1990). Hay, eso sí, muchos trabajos dispersos en la Gaceta Médica de México y otras publicaciones.

8 BARTOLACHE, J. I., (1983a), "Plan de este periódico", en su: Mercurio Volante (1772-1773), Introducción y notas de Roberto Moreno, México, UNAM, 3-11, p. 9.

9 BARTOlaChe, J. I., (1983b), "Lo que se debe pensar de la medicina”, en su Mercurio..., 45-54, p. 46. 
que los gobiernos habían protegido a los sabios condecorándolos y tratándolos como seres útiles ${ }^{10}$.

Los médicos decimonónicos buscaron, en todo momento, obtener el reconocimiento público de su trabajo y el apoyo del Estado, y lo hicieron colectivamente, por medio de sus asociaciones colegiales, antecedentes de las cuales hubo en la Nueva España desde principios del siglo XVIII ${ }^{11}$. En 1836, algunos profesores del Establecimiento de Ciencias Médicas - el cual sustituyó, a partir de 1833, a la Facultad de Medicina de la Pontificia Universidad, y reformó la enseñanza- fundaron la Academia de Medicina de Mégico. Ésta publicó un periódico -Periódico de la Academia de Medicina de Mégico - durante siete años (1836-1843). Desde el primer número de este órgano informativo se definía a la agrupación como la consulta periódica de 20 ó 30 facultativos sobre una colección de hechos, y a su periódico, como el instrumento más eficaz para extender las luces a los médicos del país, así como para señalar los peligros de prácticas médicas populares, y de cirujanos sin estudio formados al calor de las contiendas armadas ${ }^{12}$. Su función - se aseguraría años despuésera ayudar a la población que no sabía distinguir al buen del mal médico ${ }^{13}$.

Casimiro Liceaga aseguraba que para el florecimiento de las naciones era indispensable fomentar el cultivo de las ciencias, y que de ellas, la medicina era la más útil a las sociedades, pues además de curar a los enfermos, era auxilio de los legisladores ${ }^{14}$; el primer director del Establecimiento de Ciencias Médicas hacía, de esta manera, explícita la relación entre el Estado y la ciencia. Otro miembro de la Academia decía unos años después: “... no trataré de probar que la medicina es superior a todas las ciencias humanas, ni tampoco de mayor utilidad, porque uno y otro es conocido de todo el que tenga sentido común"15.

A iniciativa de Leopoldo Río de la Loza, una segunda academia se inauguró en 1851. El primer presidente fue el propio Río de la Loza, quien decía: "Si el establecimiento de las academias científicas es un bien positivo para las sociedades, el de la de Medicina en la capital de México es un verdadero servicio para la humanidad y para la ciencia"16. Esta segunda academia editó un periódico en un principio también

10 CARPIO, M., (1839), "Establecimiento de Ciencias Médicas", Periódico de la Academia de Medicina de Mégico, 4, 81-86.

11 LEÓN, N., (1914), "El quincuagenario de la Academia Nacional de Medicina", Gaceta Médica de México, 10 (3a. serie), 293-301.

12 Blaquiere (1836), "Prospecto", Periódico de la Academia de Medicina de Mégico, 1, 3-8.

13 R. A. (1841) "Errores populares relativos a la medicina: charlatanes", Periódico de la Academia de Medicina de Méjico, V-3, 121-134.

14 LiCEAGA, C., (1839), "Discurso pronunciado por el director del Establecimiento", Periódico de la Academia de Medicina de México, 4, 87-88.

15 R. A. (1841), p. 121.

16 Río DE LA LOZA, L., (1852), “Acta de la sesión inaugural de la Academia de Medicina de México (1851)”, Periódico de la Academia de Medicina de México, 1, 2-3, p. 2. 
llamado Periódico de la Academia de Medicina de México (1852), pero que de 1856 a 1858 se llamó La Unión Médica.

La fundación de sociedades médicas en el primer cuarto del siglo XIX, marcó el momento de gestación de nuevas comunidades de médicos, que cubrirían el panorama científico mexicano del resto del siglo y primeros decenios del XX, con diferentes miras y objetivos ${ }^{17}$. El 30 de abril de 1864, durante el segundo Imperio, se creó la sección de Ciencias Médicas, sexta de la Comisión Científica, Artística y Literaria de México. Ese año, apareció el primer número de su periódico la Gaceta Médica, escrito en español y en francés. En dicha creación participaron médicos extranjeros (su primer presidente fue Alberto Ehrmann, jefe de sanidad del ejército francés) y destacados clínicos mexicanos, como Miguel Jiménez y Manuel Carpio. Dichos médicos simpatizaban con los conservadores; sin embargo, de acuerdo con Ehrman y Jiménez, la Gaceta no tendría más bandera que la científica ${ }^{18}$. Esto explica que poco después de creada la sección, médicos que eran liberales decidieran unirse a ese proyecto, dando con ello una prueba de que por encima de las diferencias políticas, estaban los intereses de la ciencia y los del gremio. (Durante el resto del siglo, enemigos acérrimos en política se sentaron juntos y debatieron amigablemente en la Academia $\left.{ }^{19}\right)$. Un año después, la sección médica de la Comisión Científica se independizó con el nombre de Sociedad Médica de México. En 1870, la Sociedad se organizó en Academia, y fue la primera corporación del gremio médico que tuvo continuidad: la vida de la Academia de Medicina y de su órgano informativo, ha sido prácticamente ininterrumpida durante 130 años.

Estas sociedades tuvieron siempre un número limitado de socios, pertenecientes a una élite social. Así, la Academia de Medicina se autodefinía, en 1864, como "la porción más escogida de los médicos" 20 . Esta aseveración no era solamente producto de la subjetividad o de la sobrevaloración de uno de los sectores médicos. No puede pasar inadvertido el hecho de que, tempranamente, se habían dictado disposiciones que indicaban los honorarios que los médicos podían recibir por sus servicios, en función del caudal del enfermo, su enfermedad, el lugar y la hora de su asistencia, el tiempo empleado por el médico, el rango que tenía éste entre sus compañeros (por su edad, preparación y generosidad), su estado de salud, la naturaleza de sus ocupaciones al momento que lo llamaran, el trabajo corporal e intelectual que reclamara la

17 Trabulse, E. (1992), "Introducción”, en su Historia de la ciencia en México, 5 v., México, FCE, v. I, 15-201.

18 Ehrman y JimÉnez, (1864), "Prospecto", Gaceta Médica de México, 1, 1-2.

19 Gabino Barreda, principal responsable de la reorientación de la educación pública al triunfo de los liberales en 1867, colaboró en trabajos científicos con Miguel Jiménez, la más notable figura médica del Imperio, quien renunció a su cátedra en la Escuela de Medicina antes que jurar las Leyes de Reforma. LANDA, E., (1938), El Establecimiento de Ciencias Médicas. Su influencia notoria sobre el adelanto de la medicina en México, México, Libro del Centenario del Establecimiento de Ciencias Médicas.

20 EHRMANN y JIMÉNEZ, (1864), p. 2. 
enfermedad, el lugar donde ejerciera su profesión, el éxito de la curación e, incluso, la "representación social del enfermo", pues la atención a cierto tipo de pacientes podía afectar la moral del médico y comprometer de algún modo su nombre ${ }^{21}$. Tampoco pueden olvidarse los intentos de limitar el ingreso a la profesión, de acuerdo con criterios de clase social. En un dictamen aprobado por el Consejo Superior de Salubridad, se establecía la necesidad de que este organismo hiciera la investigación sobre la práctica, vida y costumbres de los individuos que se recibían de médicos - como antes hacía el Protomedicato-, para evitar que ejercieran "personas de baja extracción y ásperos modales" que eran "oprobio y desdoro de la profesión"22. Durante casi toda la centuria, todos los profesionales de salud, incluidos los facultativos, estuvieron divididos en de "primera, segunda y tercera clase", criterio de acuerdo con el cual pagaban impuestos al Estado.

Los médicos no incluidos en la Academia Nacional de Medicina se dieron otras formas de organización. De médicos de pocos recursos económicos residentes en la capital surgieron: la Sociedad Médica de Beneficencia, en 1852; la Sociedad Filoiátrica y de Beneficencia, la cual publicaba El Porvenir Filoiátrico, en 1868; y la Sociedad Pedro Escobedo, que publicaba El Observador Médico, también en el año 68. Con dichas asociaciones buscaban ellos contribuir al adelanto de las "ciencias médicas patrias" —entendiendo por ellas la terapéutica y la materia médica nacionales a las que consideraban descuidadas - y estrechar los vínculos de fraternidad y filantropía entre la "clase médica media" a que pertenecían. De hecho, sus agrupaciones actuaban también como sociedades mutualistas en caso de enfermedad o muerte de alguno de sus miembros. Muchas otras sociedades médicas siguieron a éstas. Cabe destacar la existencia de algunas sociedades especializadas como la Sociedad Médico-Quirúrgica Luis Muñoz, la Sociedad Oftalmológica Mexicana y la Sociedad de Obstetricia Práctica Juan María Rodríguez.

En el siglo XIX, había escuelas de medicina en Guadalajara (fundada en 1792), Oaxaca (1827), Morelia (1829), Mérida (1833), Campeche (1833), Puebla (1834), Guanajuato (1837), Nuevo León (1859), San Luis Potosí (1877). Posterior fue la creación de escuelas de medicina en Zacatecas, Pachuca y Chihuahua. La mayoría de estas instituciones académicas, lo mismo que el Establecimiento de Ciencias Médicas de la capital, padecieron discontinuidad institucional; sin embargo, en esos lugares hubo comunidades de médicos, y se crearon sociedades médicas o médicofarmacéuticas. Destacaron la Sociedad Médico-Quirúrgica Moreliana, en Michoacán; la Sociedad Médico-Farmacéutica, en Mérida; la Sociedad Médica Miguel Jiménez,

21 (1839), "Dictamen del Colegio de Medicina a quien consultó la Comisión de Gobernación de la Cámara de Diputados sobre el proyecto de arancel para honorarios de los médicos", Periódico de la Academia de Medicina de Mégico, 4, 431-435.

22 Archivo Histórico de la Secretaría de Salud (AHSSA), México, salubridad pública, ejercicio de la medicina, caja 1, exp. 35, 2 f: 1,1841 . 
en Puebla; la Sociedad Fraternal Médico-Farmacéutica, en León; la Sociedad Médica, en San Luis Potosí; la Sociedad Francisco Montes de Oca, en Pachuca y la Sociedad Médica de Zacatecas, en el estado del mismo nombre. La mayor parte de estas sociedades editaron periódicos; los Anales de la Sociedad Médica de Emulación de Guadalajara ya se publicaban en $1839^{23}$.

A las organizaciones gremiales se les veía como espacios para ratificar y rectificar opiniones y estimularse en el estudio; de ellas, surgieron las normas relacionadas con aspectos de la enseñanza y de la práctica médica. Por eso, sus organizaciones colegiales dieron a los médicos una identidad pública: ellos afirmaban tener autoridad, no como individuos, sino como miembros de una comunidad científica ${ }^{24}$. De una u otra manera, estas sociedades tuvieron un papel en el desarrollo de la medicina en México, y sobrevivieron cuando lograron tener presupuesto. De algunas de ellas no se ha hecho un solo estudio; otras, como la Academia Nacional de Medicina, sí han recibido la atención de los estudiosos, pero básicamente en sus contribuciones al desarrollo de la ciencia ${ }^{25}$. En general, faltan estudios sobre las asociaciones médicogremiales como factores de poder en el contexto social, y la democracia al interior de las mismas sociedades.

Los adelantos científicos de finales del siglo XIX favorecieron la cohesión de la profesión médica, lo cual no quiere decir que no hubiera contradicciones entre los médicos universitarios. En los años setenta y ochenta del siglo pasado, mientras la mayoría de los médicos mexicanos seguían hablando de miasmas y humores, un reducido grupo de ellos iba a Francia y Alemania a estudiar con los "príncipes de la ciencia" y llegaba con nuevos paradigmas, que no todos los facultativos asimilaban de inmediato. Otras contradicciones se dieron entre médicos de diferentes generaciones, médicos con clientela y médicos sin ella, médicos dedicados a la investigación básica y médicos dedicados a la atención clínica o a la salud pública, médicos de ciudad y médicos de los estados, médicos mexicanos y médicos extranjeros, médicos de distintas clases sociales, médicos titulados y estudiantes de medicina, y más tarde, médicos generales y médicos especialistas, y médicos de diferentes especialidades; las cuestiones éticas también fueron motivo de conflicto entre los médicos.

El Estado mexicano jugó un papel fundamental en la consolidación de la profesión médica, pero este apoyo les significó a los médicos una dependencia del Estado;

\footnotetext{
23 Acerca de sociedades médicas y sus órganos de difusión, si bien no todos están incluidos, ver FLORES (1886) y BARBERENA BLÁSQUEZ, E., BLOCK ITURRIAGA, C., (1986), "Publicaciones periódicas científicas y tecnológicas del siglo XIX: un proyecto de bases de datos". Quipu, 1, 7-26.

${ }^{24}$ STARR, P., (1991), La transformación social de la medicina en los Estados Unidos de América, México, FCE.

25 FERnÁNDEZ Del CASTILlo, F., (1956), Historia de la Academia Nacional de Medicina, México, Fournier; SOMOLINOS D'ARDoIS, G. (1964), Historia y fundación de la Academia de Medicina y su tiempo, México, Academia Nacional de Medicina.
} 
es decir, implicó influencia del poder estatal sobre el trabajo profesional de aquéllos. Además, una serie de conflictos estuvieron siempre presentes en su relación. Éstos tuvieron que ver con la imposición a los médicos de asistir gratuitamente a los enfermos pobres, acudir al llamado de cualquier enfermo o asumir ideologías políticas; también, con los intentos por parte del Estado de controlar la enseñanza y la práctica de los médicos o de ejercer acción penal contra éstos por responsabilidad en el ejercicio profesional; y principalmente, por la falta de respuesta a la exigencia de los facultativos de garantía del monopolio de la atención médica.

Alrededor de las tareas de prevenir, diagnosticar, tratar y hacer el pronóstico de las enfermedades, la medicina desarrolló una división del trabajo cada vez más compleja: farmacéuticos, parteras, enfermeras, dentistas. Los servicios de estas profesiones eran útiles y hasta indispensables para el médico; por ello no querían eliminarlas, pero sí controlarlas tanto en su preparación teórica y práctica como en su ejercicio, por ejemplo, limitando las actividades que cada una estaba autorizada a realizar. Ya dijo Dale L. Hiestand que el médico, de un modo que no tiene paralelo en ninguna otra ocupación, controla e influye su campo de actividad, y a todo aquel que osa acercarse a éste ${ }^{26}$.

\section{Cirujanos, Flebotomianos, Farmacéuticos, PaRteras, DENTISTAS y en-} FERMERAS: ASIMILACIÓN Y CONTROL

Los médicos tuvieron diferentes actitudes ante otros profesionales de la salud. Con las profesiones sanitarias cuya enseñanza y emisión de títulos dependían de las escuelas de medicina, su política fue de reconocimiento e intento de control.

La cirugía recibió poca consideración social de la medicina, al menos hasta 1831 en que ambas profesiones fueron formalmente unidas, y se dio la oportunidad a cirujanos y médicos de adquirir el título que les faltaba mediante examen ${ }^{27}$, lo cual no todos pudieron o quisieron hacer. Hacia el último tercio del siglo, ambas profesiones estaban definitivamente unidas; pero existían muchos cirujanos formados, por necesidad, durante los conflictos armados, a los que el ejército les había dado documentos militares que los acreditaban como tales. Para las autoridades sanitarias, dichos documentos podían reconocer servicios patrióticos, mas no la capacidad de ejercer como cirujano 28 .

La importancia de los flebotomianos titulados fue desapareciendo a lo largo del XIX, si bien durante las guerras ayudaron a los médicos en la ejecución de operacio-

\footnotetext{
26 Hiestand citado en Friedson, E., (1978).

27 AHSSA, salubridad pública, ejercicio de la medicina, caja 1, exp. 34, 1 f., 1841. 1869.

28 Ver, por ejemplo, AHSSA, salubridad pública, ejercicio de la medicina, caja 3, exp. 35,7 f.,
} 
nes. A finales de siglo, aún había algunos y hacían extracción de muelas, ponían ventosas simples y escarificadas, aplicaban sanguijuelas — previo mandato del médico- ponían y curaban vejigatorios y daban sangrías ${ }^{29}$; pues, en contra de la opinión de los médicos jóvenes, otros - muy prestigiados, por cierto - se quejaban de que, sin razón, se abandonaran muchas de las prácticas antiguas, y hubiese un excesivo entusiasmo por los descubrimientos modernos; se referían a la bacteriología ${ }^{30}$.

Otras profesiones sanitarias siguieron existiendo, pero las de farmacéutico y partera empezaron a enseñarse en la Escuela de Medicina y se reglamentó su práctica; también se instituyeron exámenes para los dentistas.

Los médicos que entendían la importancia de sus asociaciones gremiales, trataron de limitar, en cambio, las de otras profesiones relacionadas con la salud. Al historiador de la medicina Francisco Flores le parecía increíble que, en 1838, los médicos Febles y Benítez de la Universidad de México, hubiesen dictaminado desfavorablemente a la creación de una sociedad farmacéutica que, sin embargo, fue autorizada. Otras asociaciones del gremio fueron la Sociedad Farmacéutica, que editó el periódico La Farmacia, la Liga Farmacéutica Mexicana, la Sociedad Médico-Farmacéutica de Mérida y la Sociedad Médico-Farmacéutica de Oaxaca, entre muchas más. A lo largo de todo el siglo XIX, los profesores farmacéuticos se quejaron de la decadencia en la que había caído su profesión. Las causas a las que atribuían dicho estado eran la poca consideración que solían tenerles los médicos, los cuales, además, con frecuencia invadían su campo de actividad; la falta de una escuela especial de farmacia en la capital, pues sus cátedras dependían, como en casi todos los estados, de la Escuela de Medicina; la desunión de los miembros del gremio, los abusos de los vendedores de medicamentos sin título; el desinterés hacia su profesión de parte del Estado; la "visita inquisitorial" de la inspección de boticas realizada por las autoridades sanitarias; la competencia que les significaban los medicamentos extranjeros de patente; la proliferación de farmacias; y la ignorancia de la sociedad mexicana ${ }^{31}$. Los farmacéuticos de la capital no tendrían nunca una escuela de farmacia; pero en 1916, iniciaría labores la Escuela Nacional de Ciencias Químicas, donde se crearía la carrera de químico-fármaco-biólogo ${ }^{32}$.

Desde el siglo pasado hubo intentos por parte del Estado y de la profesión médica, para reemplazar a las parteras por mujeres alfabetas entrenadas en las escuelas de medicina, que fuesen auxiliares de los facultativos. La partera profesional nació así

\footnotetext{
29 FLORES, F., (1886).

30 CARMONA Y VAlle, M., (1897), "Algunas consideraciones relativas a la práctica antigua y moderna de la medicina", Memorias del II Congreso Médico Mexicano. San Luis Potosí, 5-8 de noviembre de 1894, 2 v., México, Secretaría de Fomento, v. I, 22-28.

31 CoEllar, A., (1896-1897), "Consideraciones sobre el estado actual de la farmacia en México", La Farmacia, V-7 y 12; VI-1 y 2; 182-186, 269-277, 13-23 y 31-42.

32 GARCía FERNÁNDEZ, et al., Historia de una facultad 1916-1983, UNAM, 1985.
} 
con el doble carácter de actividad necesaria a la profesión médica y subordinada a ella, y de práctica represora de la actividad de las parteras tradicionales, competitiva de la medicina académica ${ }^{33}$. Pero los médicos universitarios tenían contradicciones no sólo con las parteras empíricas sino, incluso, con las parteras tituladas preparadas por ellos, las cuales eran preferidas por las mujeres porque los facultativos eran demasiado propensos a utilizar técnicas quirúrgicas perjudiciales para la madre y su producto; si bien los médicos achacaban esa preferencia al "falso pudor" de las pacientes, y a que éstas no sabían distinguir al veradadero del falso saber. En 1887, se establecieron en la Escuela Nacional de Medicina tres cátedras de perfeccionamiento, y una de ellas fue la de ginecología teórico-práctica. A partir de la instauración de la ginecología como especialidad, se intensificó la presión estatal para controlar a las parteras, aun a aquéllas con título legal, pues la naciente especialidad era incompatible con el número de partos atendidos por parteras tituladas y tradicionales. En 1892, el Ministerio de Gobernación publicó un reglamento para las parteras tituladas, en el cual se observa el intento de los médicos universitarios de irlas desplazando de la atención a parturientas y puérperas - pues sólo les permitía intervenir en partos sin complicaciones-, además de utilizarlas para convencer a las pacientes y a sus familiares de la importancia de recurrir a los servicios médicos ${ }^{34}$. El reglamento provocó las quejas de las parteras; un mes después de la publicación de aquél en el Diario Oficial, la Sociedad Liga de Parteras, formada por profesoras tituladas de la Facultad de Medicina de México, pidió al presidente de la república la reforma del Reglamento de Parteras, que - alegaba - violaba el Reglamento de la Escuela de Medicina, pues les prohibía realizar prácticas para las cuales se les había preparado ${ }^{35}$; sin embargo, se dictaminó en contra de la petición de las parteras. En los aranceles para las diferentes profesiones sanitarias - que eran un instrumento para controlar a dichas profesiones, así como para marcar la jerarquía entre ellas-, puede verse con claridad el grado de medicalizacción que hacia 1910 tenía el parto atendido por médicos, además del hecho de que dicha intervención tenía un alto costo para las usuarias, a diferencia del trabajo de las parteras que estaban autorizadas a cobrar muy poco por sus servicios ${ }^{36}$. A principios del siglo $\mathrm{XX}$, se exigió como requisito para inscribirse en la carrera de partera, haber obtenido antes el título de enfermera, y la

33 MARTínez BeníteZ, M. M., et al. (1985), Sociología de una profesión. El caso de la enfermería, México, Nuevomar.

34 "Reglamento al que deberán sujetarse las parteras en el ejercicio de su profesión" (1892), La Medicina Científica, 11, 168-169.

35 Archivo Histórico de la Universidad Nacional Autónoma de México (AHUNAM), México, Escuela Nacional de Medicina, institutos y sociedades médicas, Sociedad Liga de Parteras, caja 42, exp. 1, f. 1-2.

36 "Arancel de médicos, flebotomistas y parteras del estado de Michoacán", AHSSA, salubridad pública, Presidencia, Secretaría, caja 6, exp. 26, f. 4-13, 1910. 
partería profesional fue definitivamente eliminada en los años cincuenta, en favor de la ginecología ${ }^{37}$.

La de dentista llegaría a ser, con el tiempo, una profesión autónoma, pero no fue el caso en su surgimiento. En el siglo pasado, México carecía de una institución formal de enseñanza dental. Desde 1840, los títulos los daba el Consejo Superior de Salubridad, mediante un examen de suficiencia que hacía la Escuela de Medicina, pero los maestros examinadores no eran dentistas sino médicos; por eso, los dentistas estuvieron, durante mucho tiempo, a la sombra de aquéllos. La primera agrupación dental del país fue la Sociedad Odontológica Nacional Mexicana, creada en 1887, para ingresar en la cual era necesario tener el título correspondiente; poco después, salió a la luz el periódico Arte Dental, órgano oficial de la Sociedad. En 1896, se organizó la Sociedad Dental Mexicana, cuyo objetivo fundamental era crear en México una escuela de odontología; seis años después, se obtuvo un acuerdo presidencial en que se establecía la necesidad de una escuela del ramo. El Consultorio Nacional de Enseñanza Dental, anexo a la Escuela de Medicina, se inauguró el 19 de abril de 1904, y obtuvo su independencia de la Escuela de Medicina en $1911^{38}$.

En 1887, se graduó Matilde Montoya, primera médica mexicana, y detrás de ella se inscribieron otras. El momento en que las mujeres empezaron a solicitar su ingreso en las escuelas de medicina, coincidió con el de la creación de la profesión de enfermera. Hacia finales del siglo XIX, estaba mundialmente establecido que los estudiantes de medicina necesitaban hospitales donde realizar sus estudios clínicos, y que los buenos hospitales requerían de enfermeras. El Hospital de Maternidad e Infancia, donde se formaron las primeras enfermeras mexicanas, las había aceptado de buen grado; pero el Hospital General y el Manicomio de la Castañeda (para enfermos mentales) -inaugurados en 1905 y 1910, repectivamente, y dotados de todos los avances médicos de su tiempo-, las hicieron indispensables. En 1898, se estableció una escuela práctica y gratuita para enfermeras, pensando en el Hospital General que entonces se construía ${ }^{39}$. También en provincia se establecieron cátedras de enfermería; en 1910, había cinco escuelas de enfermería en el país ${ }^{40}$. A diferencia de las médicas universitarias y de las médicas indígenas que eran autónomas, las enfermeras estuvieron siempre subordinadas al poder médico. La formación que se daba a las futuras enfermeras incluía, tanto en el aprendizaje como durante la práctica, la importancia de seguir cuidadosamente las prescripciones del médico y sus órdenes, recordándoles siempre que la enfermera no era ni podía ser médico, y en los expe-

\footnotetext{
37 MARTÍNEZ BeníteZ, M. M., et al. (1985).

38 Zimbrón LeVy, A., FeIngold STEINER, M. (1990), Breve historia de la odontología en México, Cuernavaca, CRIM, UNAM.

39 AHSSA, México, salubridad pública, establecimientos dependientes, Escuela de Enfermeras del Hospital General. caja 1, exps. 33 y 34, 9 y 2 f., 1902-1903 y 1898.

40 MARTínez BENÍTEZ, M. M., et al. (1985).
} 
dientes de las alumnas se valoraba el que éstas fueran sumisas ${ }^{41}$. Los estudios de enfermería fueron dependientes de la Escuela de Medicina, donde médico era el director y médicos también sus examinadores y maestros. La organización profesional de su gremio, la Asociación Mexicana de Enfermeras, se crearía tardíamente, en 1947, y al año siguiente se separarían de la Escuela de Medicina, pero sin conseguir autonomía o autoridad ${ }^{42}$.

\section{RELIGIOSOS, HOMEÓPATAS Y MÉDICOS INDÍGENAS: DESCALIFICACIÓN Y COMBATE}

Cuanto más "invade" una profesión sanitaria el área que los médicos consideran de su competencia exclusiva, mayores conflictos se generan entre ellos. Ejemplo de esto fue la lucha librada en el siglo XIX entre los médicos universitarios, de una parte, y los religiosos que prestaban servicios médicos, los homeópatas y los médicos indígenas, de la otra.

Durante la Colonia, la Iglesia había sido la institución fundamental en el patrocinio, construcción, sostenimiento y administración de los hospitales. En opinión de Cooper, esto se debía quizá a la relación de la enfermedad, el sufrimiento y la muerte con la filosofía clerical ${ }^{43}$; pero durante la gestión borbónica, se vislumbró la posibilidad de que el Estado controlara las políticas de salud, prescindiendo de la labor de los religiosos. Y es que la lucha por imponer la prioridad del poder civil sobre el eclesiástico se consideraba cuestión esencial para el fortalecimiento del Estado moderno ${ }^{44}$. A partir de entonces, la búsqueda del control de la atención médica fue no sólo una de las formas de lucha política entre el clero y el Estado, sino uno de los principales ejes de dicha lucha ${ }^{45}$, y los médicos jugaron un papel importante en los procesos sociales de secularización y racionalización ${ }^{46}$. El 23 de junio de 1813 , se publicó un decreto referente a la instrucción para el gobierno económico-político de las provincias, que estipulaba las obligaciones de los ayuntamientos, dentro de las que estaba vigilar la salubridad de los pueblos. Este decreto preveía que cada año se formase en todo pueblo, para cuidar de la salud pública, una Junta de Sanidad, com-

41 AHSSA, salubridad pública, establecimientos dependientes, Escuela de Enfermeras del Hospital General, caja 1, exps. 7, 8 y 18, 6, 37 y 6 f., 1903, 1903-04 y 1904.

42 MARTÍNEZ BENÍTEZ, M. M., et al. (1985).

43 COOPER, D. B., (1980), Las epidemias en la ciudad de México 1761-1813, México, IMSS.

44 SALDAÑA, J. J., (1989), "La ciencia y el Leviatán mexicano", Actas de la Sociedad Mexicana de Historia de la Ciencia y la Tecnología, v. I, México, 37-52.

45 MORENO CUETO, E., et al. (1982), Sociología histórica de las instituciones de salud en México, México, IMSS.

46 Acerca de el papel desempeñado por los científicos de otras disciplinas en los proyectos de modernización del Estado nacional, consultar SALDAÑA, J. J., AZUELA, L. F., (1996), "De amateurs a profesionales. Las sociedades científicas mexicanas del siglo XIX”. Quipu, 2, 35-172. 
puesta del alcalde primero, del cura párroco más antiguo, de uno o más regidores, de uno o más vecinos y de uno o más médicos. Leyes promulgadas después de la guerra de Independencia, siguieron incorporando a los religiosos en los organismos sanitarios (Michoacán, 1825; Tamaulipas, 1841; Jalisco, 1850...)47. Más tarde, los liberales expropiaron los hospitales al clero; pero dicha expropiación no siguió una marcha constante: se hacía efectiva cuando los liberales ocupaban el poder, y la Iglesia los recuperaba con los gobiernos conservadores. La expropiación tuvo su punto culminante en 1856, con la puesta en práctica de las leyes de desamortización. En 1874, el presidente Lerdo de Tejada se enfrentó al clero, personificado en las Hermanas de la Caridad, al decretar su expulsión de los hospitales de todo el país ${ }^{48}$. Las religiosas, sin embargo, siguieron actuando en hospitales privados y entre la población, proporcionando cuidados a la cama del enfermo. Dichos cuidados eran fundamentalmente espirituales pero, lógicamente, ellas también acumulaban experiencia clínica, y no estaban supeditadas al poder médico sino a la autoridad eclesiástica. Finalmente, el movimiento de los médicos por la medicina científica — que encontró la causa y los mecanismos de trasmisión de muchas enfermedades, y que opuso a la filantropía religiosa, la filantropía en ciencia - afectó más a la Iglesia en su intento de controlar los servicios de atención a la salud, que todas las disposiciones estatales ${ }^{49}$.

El sistema homeopático — que criticaba el abuso de la cirugía y la polifarmaciaencontró en México, por un lado, un terreno propicio para su desarrollo y, por el otro, la franca oposición de la medicina institucional. Miembros de la escuela oficial reconocían que había homeópatas con más clientela que los médicos; pero esto se debía - aseguraban - a que la audacia del charlatán aseguraba su éxito; en cambio, el sabio era modesto, lo que le perjudicaba para impresionar al vulgo. Decían también que, aun de ser cierta la teoría de Hanhemann, mientras los homeópatas no tuviesen cátedras, hospitales, cursos de clínica y anfiteatros, no podrían "ni sentarse junto a los médicos" $"$. En realidad, los homeópatas consideraban a su práctica como la misma ciencia médica pero reformada, y tuvieron pronto escuelas y consultorios, además de organizaciones gremiales y periódicos. En 1869, a iniciativa de Julián González se estableció el Instituto Homeopático Mejicano; otras sociedades homeopáticas fueron el Círculo Homeopático Mexicano, la Sociedad Médico-Homeopática Mexicana y la Sociedad Hahnemann. Tempranamente, los homeópatas difundieron sus ideas por medio de publicaciones periódicas: La Homeopatía en México, La Homeopatía en el Mundo, El Estudio, El Faro Homeopático y La Reforma Médica, también entre otras varias. En 1893, con apoyo estatal se creó el Hospital Nacional

47 CONSEJO SUPERIOR DE SALUBRIDAd (1910), La salubridad e higiene pública en los Estados Unidos Mexicanos, México, Casa Metodista de Publicaciones.

48 MURIEL, J., (1991), Hospitales de la Nueva España, 2 vol., México, UNAM / Cruz Roja Mexicana.

49 COE, R. M., (1973), Sociología de la medicina, Madrid, Alianza.

50 PATiÑo, F., (1881), "La libertad de profesiones", La Escuela de Medicina, 14, 161-165. 
Homeopático, lo que significó un paso fundamental en la institucionalización de esta doctrina. Los homeópatas se empeñaron, también, en regularizar la enseñanza de la medicina homeopática, lo cual lograron en 1895, con el establecimiento, por decreto presidencial, de la Escuela Nacional Homeopática. El poder legitimador del Estado prendió la mecha del debate entre alópatas y homeópatas, debate que se dio en dos niveles: un nivel intrateórico, en el que participaron las comunidades médicas de éstos y aquéllos, que disputaron la coherencia y la autoconsistencia de una y otra práctica científica; y un nivel extrateórico, en el que entraron en juego una serie de intereses de tipo gremial y, desde luego, el papel rector del Estado porfiriano quien dotó de legitimidad institucional a la homeopatía, por medio de la creación del hospital, primero, y de la escuela, después. ${ }^{51}$ Los médicos alópatas auguraron siempre la pronta caída de la homeopatía ${ }^{52}$. Sin embargo, en vísperas de la revolución, los homeópatas tenían sociedades en las que se reunían sus practicantes; organizaban congresos y convocaban a concursos; difundían sus ideas por medio de periódicos; se relacionaban con sus colegas en el extranjero; y habían logrado la institucionalización de la enseñanza y la práctica de la homeopatía, por medio de una escuela nacional que controlaba quiénes podían llamarse a sí mismos homeópatas, y de un hospital - también nacional- donde éstos ejercían.

Pero la mayoría de la población mexicana del siglo XIX, no recurría ni a la alopatía ni a la homeopatía, sino a la medicina indígena y popular, así como a la medicina doméstica. Cuando en 1888 fue creado el Instituto Médico Nacional, que tenía entre sus funciones estudiar la flora medicinal indígena, se invitó a la población a enviar información para que aquél investigara. Decían: "Muchas verdades vulgarizadas en el campo y poblaciones pequeñas, son enteramente ignoradas en México por profesores que pudieran aprovecharlas, así como muchas vulgaridades pasan en el sencillo pueblo y gente crédula como verdades indiscutibles" 53 . El mensaje era claro; sólo la ciencia podría discernir entre la verdad y el error. Se hablaba de "conocimiento vulgar"; la sabiduría centenaria de los médicos indígenas - que eran terapeutas socialmente reconocidos- sencillamente se ignoraba, como se ignoraba que la medicina indígena no era institucional pero sí estructurada. Y es que al no contemplar otros modelos que los que la hacían funcionar, la medicina era incapaz de dar la más mínima explicación sobre los descubrimientos de otras terapéuticas o modelos, excepto en términos de empirismo" 54 .

51 AzUEla, L. F. y CARrillo A. M., "El juego de la legitimación del saber. La polémica en torno de la institucionalización de la homeopatía en México", ponencia presentada en el VI Congreso Nacional de Filosofía, Chihuahua, oct. 11 de 1991.

52 BARREDA, G. (1902), "La homeopatía o juicio crítico sobre este nuevo sistema", Revista Positiva, $17,137-158$.

53 (1889), “Invitación", El Estudio, 4, 49-51, p. 49.

54 Clavreul, J. (1983), El orden médico, Barcelona, Argot. 
Los médicos decimonónicos menospreciaron al resto de los saberes médicos, aun en los casos en los que ni unos ni otros tenían respuesta a los problemas de salud ${ }^{55}$, pero este intento de exclusión se agudizó a finales del siglo XIX cuando grandes avances médicos revolucionaron la comprensión y el tratamiento de las enfermedades. Estos avances de investigación en México se concretaron en los institutos nacionales de investigación: Médico (1888), Antirrábico (1888), Patológico (1899) y Bacteriológico (1905).

A pesar de lo reducido de su número (en 1910, había 3.021 médicos para $15.160,377$ habitantes $^{56}$ ), los médicos de este periodo exigían del Estado la garantía del monopolio de la atención sanitaria; éste, sin embargo, no se los concedió. Cierto que a lo largo del siglo XIX, hubo leyes que limitaron la acción de los médicos indígenas; en casos extremos se les destinó, incluso, al servicio militar a principios de los años cuarenta ${ }^{57}$. Pero la experiencia mostraría que el control oficial no bastaba; mientras la población no creyera en la medicina académica, la consulta sería escasa. Además, estas leyes no podían estar por arriba de la carta magna: la Constitución liberal de 1857 planteaba en sus artículos $3^{\circ}$ y $4^{\circ}$ la libertad de enseñanza y la libertad de profesiones, así como que la ley determinaría qué profesiones necesitaban título para su ejercicio, pero ni durante el periodo de la República restaurada ni durante el porfiriato se expidió la ley orgánica de los mismos ${ }^{58}$. Al igual que en Estados Unidos, en México algunos demandaban la libre competencia en medicina, pues después de la independencia había un sentimiento contra los profesionalismos y los elitismos, que se vio plasmado en los mencionados artículos. La mayoría de los médicos, sin embargo, lucharían de manera resuelta y constante porque se reglamentara el ejercicio de la medicina. Ellos habían estudiado para obtener un título que fuese garantía de una posición privilegiada en la sociedad, y sentían que la libertad de profesiones obstaculizaba sus posibilidades de ascenso social.

Las otras profesiones sanitarias también tenían contradicciones entre sí: farmacéuticos versus religiosas que atendían farmacias, parteras tituladas versus parteras empíricas, homeópatas versus farmacéuticos, dentistas versus flebotomianos... Para los profesionales de la salud que tenían un título, los conocimientos y habilidades para curar sólo podían obtenerse asistiendo a las universidades. La práctica de "los sin título" era ilegal, porque la ley la prohibía; atentatoria, porque ponía en peligro la

55 AGUiRRe BeltráN, G., (1986), "La medicina indígena en el siglo XIX", México Indígena, 9, 6-7.

56 GonZÁlez NAVARro, M., (1970), "La vida social", en Cosío Villegas (coord.) Historia moderna de México, 10 v., México, Hermes, v. III.

57 Álvarez AmÉzQuiTA, José et al. (1960), Historia de la salubridad y de la asistencia en México, 4 v., México, IMSS, v. II.

58 Sobre los debates acerca de este asunto en el Congreso de la Unión, consultar BAZANT, M. (1982), "La República Restaurada y el porfiriato", en ARCE et al., Historia de las profesiones en México, México, Colmex, 128-222. 
salud pública; y criminal, porque privaba de la salud o de la vida. En cambio, para el Estado la enseñanza universitaria no era el único criterio que habilitaba a un hombre para practicar la medicina. La Constitución de 1917 tampoco dio a médicos, farmacéuticos y parteras titulados el monopolio para tratar al enfermo. Para obtenerlo, los profesionales de la salud tendrían que esperar hasta mediados del siglo $\mathrm{XX}^{59}$.

\section{EL DISCURSO TOTALITARIO DEL ORDEN MÉDICO}

En general, los médicos se quejaron tanto en la época colonial como en el México independiente, la República restaurada y el porfiriato, de su falta de clientela; ni los poderosos recurrían sólo a ellos. Casi terminaba el siglo XIX, cuando el delegado del Consejo Superior de Salubridad en Manzanillo, después de informar que era el único médico en 94 kilómetros a la redonda, y que tampoco había botica en el lugar, aseguraba que ganaba muy poco pues la clientela huía del médico como no huía de las epidemias $^{60}$.

En opinión de Freidson, nadie puede ser obligado a consultar a un médico ${ }^{61}$. En realidad, en México, como en muchos otros países, en innumerables ocasiones, el Estado forzó a la población a consumir atención médica; por ejemplo, en las campañas contra la fiebre amarilla y el paludismo, la peste o la tuberculosis de principios de este siglo (las dos primeras iniciadas en 1903, la tercera llevada a cabo en 1902-03, y la cuarta, a partir de 1907). En estas campañas - realizadas en puertos, fronteras y ciudades importantes, y ligadas al proyecto económico de la dictadura porfiriana-, las autoridades sanitarias aislaban a los enfermos contra su voluntad y la de sus allegados, en lazaretos o casas de salud, con lo que poco a poco fueron arrancando a los enfermos de la familia para ponerlos en la esfera del servicio profesional. Prohibían, asimismo, que los enfermos contagiosos deambularan por las calles, y mandaban derribar las barracas que consideraban inadecuadas para habitación ${ }^{62}$, hechos que algunos autores definen como una forma radical de autoridad médica institucionalizada ${ }^{63}$.

Al finalizar el periodo estudiado, la burocracia sanitaria estaba autorizada por los códigos sanitarios (de 1891, en la capital, y posteriores en la mayoría de los estados) a penetrar en cuarteles, cárceles, asilos, templos, mercados, accesorias, rastros, hospita-

59 "Ley reglamentaria de los artículos $4^{\circ}$ y $5^{\circ}$ constitucionales, relativos al ejercicio de las profesiones en el Distrito y territorios federales", Diario Oficial, México, mayo 26 de 1945, 1-9.

60 AHSSA, salubridad pública, epidemiología, caja 3, exp. 5, s/nf.

61 FREIDSON, E., (1978).

62 CARrillo, A. M., "Reglamentarismo y vida cotidiana: la salud pública en el porfiriato", en VIESCA, C. (coord.) Historia general de la medicina en México. S. XIX, México, Academia Nacional de Medicina / Facultad de Medicina, UNAM, en prensa.

63 StARR, P., (1991). 
les, farmacias, mesones, vecindades, teatros, circos, cinematógrafos, escuelas, prostíbulos, panteones, barcos, ferrocarriles, fábricas, parques, bosques y viviendas, para reglamentar y vigilar la higiene privada y pública, lo que implicó una extensión extraordinaria del campo y de los poderes médicos a todos los espacios de la vida; lo que Weber llamaba la secularización ${ }^{64}$ y Foucault la medicalización de la vida cotidiana ${ }^{65}$.

Desde 1842, había sido creado el Consejo Superior de Salubridad en el Distrito Federal, el cual dependía de la Secretaría de Gobernación y durante los siguientes 75 años fue la máxima autoridad sanitaria del país. En el porfiriato (1876-1910), el Consejo amplió su influencia a los puertos y fronteras, a pesar de la oposición de los gobiernos locales que alegaban insconstitucionalidad en la intromisión del gobierno federal en los asuntos sanitarios de los estados. El poder médico fue mayor a partir de 1917, en que el Congreso Constituyente de Querétaro acordó crear el Departamento de Salubridad Pública, dependiente directamente del presidente de la república, cuyas disposiciones serían de observancia obligatoria en todo el país.

Ya en la XXXII Reunión de la Asociación Americana, Canadiense, Mexicana y Cubana de Salubridad Pública, realizada en 1906, decía el médico mexicano José Mesa y Gutiérrez que la legislación de la profilaxis era tan importante como la profilaxis misma. La evolución de la higiene tenía lugar en la mente de un "selecto grupo de hombres altamente talentosos" que dedicaban su vida entera al mejoramiento de la humanidad. El resultado de sus investigaciones debía aplicarse de manera inmediata en la forma de leyes, para beneficio de la comunidad, que no tenía ni el tiempo ni la oportunidad de aprender esos asuntos. Dicha legislación — que podría introducirse hasta en "la sagrada privacidad del hogar", modificaríy hábitos y protegería a la población "de su propia ignorancia"66.

Gracia explica que detrás de las teorías paternalistas en salud ha habido, durante más de un milenio, influencia de Platón y Aristóteles, para quienes la función del gobernante no es otra que mediar entre los mundos de las ideas y de los hombres. Por eso, el orden moral no surge de la libre aceptación sino de la imposición: obligando a los súbditos a cumplir con el orden moral impuesto, el gobernante platónico promociona la libertad de todos los individuos. Tal es la justificación moral del absolutismo político. "Y si el término del monarca o gobernante se sustituye por el del médico, y el del súbdito por el del enfermo, se tiene una imagen rigurosamente fiel de lo que

64 Citado en HABermas, J., (1980), "La ciencia y la tecnología como ideología", en BARNES et al., Sociología de la Ciencia, Madrid, Alianza Universidad, 344-364.

65 Foucault, M., (1980), "Crisis de un modelo en la medicina", Medicina Tradicional, 9, México, 123-147.

66 MESA Y GUTIÉRREZ, J., (1907), "Contribution to the study of problems of national and international sanitary legislation", Public Health Papers and Report. XXXIV Annual Meeting. México City, v. XXXII, Chicago, The Journal of Infectious Diseases, 30-37, p. 30. 


\section{PROFESIONES SANITARIAS Y LUCHA DE PODERES EN EL MÉXICO DEL SIGLO XIX}

tradicionalmente ha sido el despotismo ilustrado del médico"67. El médico pretende siempre lograr la restitución del orden natural, o sea un bien objetivo, por lo que debe imponérselo al paciente aún en contra de la voluntad de éste. Si el enfermo difiere en cuanto a lo bueno para sí, esto se debe a un error subjetivo, que no puede tener los mismos derechos que la verdad objetiva. El médico, pues, no es sólo agente técnico, sino también moral, y el enfermo un paciente necesitado de ayuda tanto técnica como moral ${ }^{68}$.

En el periodo 1821-1917 —que tuvo entre algunas de sus principales tendencias la profesionalización y la institucionalización - hubo un enfrentamiento prefabricado por los médicos, entre la ignorancia y la sabiduría, la superstición y la ciencia, la charlatanería y la ética, el abuso y el humanitarismo $\mathrm{Al}$ igual que en otros países, fue sobre todo en nombre del bienestar de la humanidad como se ejerció el dominio médico sobre otras profesiones sanitarias y el derecho de imponerse a los enfermos ${ }^{69}$. Cuando en 1874, un médico y un farmacéutico elaboraron un dictamen sobre salubridad en que solicitaban la prohibición del despacho gratuito de medicamentos hecho por las Hermanas de la Caridad, insistían - como en tantos otros casos- en que los intereses que los animaban no eran los pecuniarios, sino la salubridad y el celo por el bien público ${ }^{70}$. A las acusaciones que las parteras tituladas hacían a los médicos que habían elaborado el Reglamento de Parteras de 1892, de quererlas despojar de la parte más lucrativa de su profesión, éstos contestaban que era un desatino pensar que los caballeros del cuerpo facultativo pudieran estar guiados "... por una aspiración tan triste como la de disputar a las parteras los despojos pecuniarios de una cuantas enfermas, abusando para ello de su elevada posición oficial"'11; su único interés era el bienestar de las madres y los niños.

Pero aunque los médicos prometían la integridad de sus miembros por adhesión a un código ético, había quejas de los jóvenes médicos de no haber sido instruidos durante sus estudios acerca de cuáles eran sus deberes y cómo debían conducirse con los enfermos, con los otros médicos, con los disidentes, con los farmacéuticos, con las parteras y con los curanderos ${ }^{72}$.

67 GRACIA, D., (1990a), "La bioética médica", en Organización Panamericana de la Salud, Bioética. Temas y perspectivas, publicación científica 527, Washington, OPS, 3-7, p. 4.

68 GRACIA, D., (1990b), “¿Qué es un sistema justo de servicios de salud? Principios para la asignación de recursos escasos", en Organización Panamericana de la Salud, Bioética...,187-201.

69 Clavreul, J., (1983).

70 EGEA Y GALINDO RAMíREZ, (1874), "Dictamen sobre salubridad. Inhabilidad de los individuos que carecen de título legal para ejercer las profesiones que lo requieren en su ejercicio, según el artículo $3^{\circ}$ de la Constitución federal", El Observador Médico, 9, 132-137.

71 QUIJANO, A. A., (1892), "Dos palabras a propósito de las parteras y su reglamento", La Medicina Científica, 11, 175.

72 SosA, S., (1889), "Deberes del médico", El Estudio, 15, 225-226. 


\section{ANA MARÍA CARRILLO}

\section{A MANERA DE CONCLUSIÓN}

Para el historiador de la medicina del siglo XIX mexicano, la conversión de la medicina de "oficio" en "profesión" es mucho más que un indicador del cambio de estatus de una práctica socialmente reconocida. Es una clave epistemológica para hacer visible, primero, e inteligible después, el sentido de un proyecto colectivo dentro de un denso orden de acontecimientos diversos y convergentes, un espectáculo que desborda el discurso de lo gremial para redefinir no sólo la jerarquía de los saberes, sino, sobre todo, la reestructuración del orden institucional.

Esa reestructuración se refiere tanto a las instituciones del Estado, como a otras formas de la vida social que la profesión médica cala en la densidad de lo cotidiano. Como se trata de una dialéctica que anuda permanentemente el orden institucional con la fluidez del acontecimiento, el historiador se ve expuesto a dos situaciones que se reiteran: por una parte, la sensación de que en el período estudiado "pasan demasiadas cosas" y, en consecuencia, que el discurso histórico se vuelve obsesivamente totalitario, empeñado en la labor de abarcarlo todo; por otra, la impresión de que la diversidad de lo real se reduce a tres o cuatro imágenes repetitivas: el reglamentarismo, la institucionalización, la profesionalización. Se trata de grandes imágenes canónicas que van forjándose al lado y al ritmo de la redefinición política de un país que ha entrado en un violento y profundo proceso de cambio, que ha optado por la modernidad y que es consciente de que su misión institucionalizadora deberá enfrentar, en primer lugar, la diversidad económica, política, geográfica, incluso étnica.

El modelo médico forjado de 1821 a 1917, fue determinante del conjunto de relaciones que los profesionales médicos establecieron con el Estado, con la población y con los otros saberes médicos. La creación de sus organizaciones colegiales; el nacimiento de sus órganos de información; la reorganización de su saber; la explicitación de su orientación de servicio; el control de los integrantes del gremio; la imposición de su práctica a la población; y los mecanismos de exclusión, monopolización y control de otras profesiones sanitarias, que se consolidarían en la presente centuria, están dados - y de ahí su importancia— en el siglo XIX.

\section{AGRADECIMIENTOS}

El contenido de este artículo forma parte de mi tesis doctoral Epidemias, saberes médicos y salud pública en el porfiriato, que dirige el doctor Juan José Saldaña. Muchas de las reflexiones aquí expuestas, son producto del trabajo realizado en su seminario en la Facultad de Filosofía y Letras de la UNAM; también se vieron enriquecidas con las acertadas observaciones del maestro Carlos Zolla. Por supuesto, ninguno de ellos es responsable de sus limitaciones. 